\title{
Comparison of the effects of pretreatment intravenous fentanyl or intravenous lidocaine on suppression of fentanyl-induced cough in children: a randomized, double-blind, controlled clinical trial
}

\author{
Mitra Golmohammadi ${ }^{1}$, Shahryar Shajiee ${ }^{2}$, Shahryar Sane ${ }^{3}$, Mohammad Valie ${ }^{4}$
}

${ }^{1}$ MD., Anesthesiologist, Assistant Professor, Department of Anesthesiology, Faculty of Medicine, Urmia University of Medical Sciences, Urmia, Iran

${ }^{2}$ MD., Anesthesiology Resident, Department of Anesthesiology, Faculty of Medicine, Urmia University of Medical Sciences, Urmia Iran

${ }^{3}$ MD., Anesthesiologist, Associate Professor, Department of Anesthesiology, Faculty of Medicine, Urmia University of Medical Sciences, Urmia Iran

${ }^{4}$ MD., Pediatric Surgeon, Assistant Professor, Department of Pediatric Surgery, Faculty of Medicine, Urmia University of Medical Sciences, Urmia Iran

\section{Type of article: Original}

\begin{abstract}
Background and aim: The injection of fentanyl usually causes coughing during induction of anesthesia. Based on a few studies about effects of lidocaine and the fact there is no study concerning the effect of fentanyl on fentanyl-induced cough in pediatric patients, the aim of this study was to compare the effectiveness of low dose of fentanyl with lidocaine in prevention of fentanyl-induced cough in children.

Methods: This randomized double-blind controlled clinical trial study was conducted at Motahari Hospital between February and August 2017 in Urmia (Iran). One hundred patients, aged 2-10 years, of class I or II ASA status who were candidates for elective herniorrhaphy under general anesthesia were enrolled in this study. They were randomly divided into three groups. One minute before the administration of $2 \mu \mathrm{g} / \mathrm{kg}$ fentanyl during induction of general anesthesia, Group I received $1.0 \mathrm{mg} / \mathrm{kg}$ lidocaine $(\mathrm{n}=33)$, Group II received $0.5 \mu \mathrm{g} / \mathrm{kg}$ fentanyl $(n=34)$ and Group III received normal saline as a control group $(n=33)$. The data were analyzed by STAT version 13. The incidence and severity of cough were determined across groups by using ANOVA and Chi-square tests. Multiple logistic regression was also used to examine the association between the outcome of cough incidence and clinical interventions as the exposures after adjusting for study covariates.

Results: The highest incidence of cough was found in the Group III (54.5\%) versus $32.4 \%$ and $21.1 \%$ in Group II and Group I subsequently $(\mathrm{p}=0.02)$. We have also found significant difference in the incidence of cough among group one and three $(\mathrm{p}=0.005)$, and among group two and three $(\mathrm{p}=0.045)$. No statistically significant difference has been detected between group one and two. The severity of cough was significantly higher in Group III compared to Groups I and II ( $\mathrm{p}=0.01)$.The time of onset of cough was similar across groups. No side effects were reported after intervention in this study

Conclusion: This study found that pretreatment with fentanyl $0.5 \mathrm{mg} / \mathrm{kg}$ or $1 \mathrm{mg} / \mathrm{kg}$ lidocaine is an effective approach to reducing the incidence and severity of fentanyl-induced cough in children.

Trial registration: The trial was registered at the Iranian Registry of Clinical Trials (http://WWW.irct.ir) with IRCT number: IRCT2016112027677N5.

Funding: This study was not granted or funded by any institution.

Keywords: Anesthesia, Fentanyl, Lidocaine, Cough, Children, Pretreatment
\end{abstract}

\section{Corresponding author:}

Assistant Professor Dr. Mitra Golmohammadi, Department of Anesthesiology, Faculty of Medicine, Urmia University of Medical Sciences, Urmia Iran.

Tel: +9833468967, Fax: +98.33469939, Email: mitragolmohammadi@yahoo.com

Received: March 07, 2018, Accepted: May 13, 2018, Published: June 2018

iThenticate screening: May 13, 2018, English editing: June 12, 2018, Quality control: June 14, 2018

This article has been reviewed / commented by four experts

Ethics approval: IR.UMSU.REC.1394.386

(C) 2018 The Authors. This is an open access article under the terms of the Creative Commons Attribution-NonCommercialNoDerivs License, which permits use and distribution in any medium, provided the original work is properly cited, the use is non-commercial and no modifications or adaptations are made. 


\section{Introduction}

Fentanyl as a selective $\mu$-opioid receptor agonist is the preferred narcotic in anesthesia, especially with respect to a pre-induction adjunct agent. Major preferences of this drug include; rapid onset, the brief duration of action, cardiovascular stability, and low histamine release. Despite the antitussive effects of opioids being well known, fentanyl administration by intravenous bolus provokes coughing in up to $50 \%$ of patients (1-3). Fentanyl-induced cough is usually a benign and self-limiting phenomenon, but rarely, it can be accompanied with some adverse effects such as; rising intraocular, intracranial, and intra-abdominal pressures, which may require prompt treatment. (4-5). Jong-In Han et al. demonstrated that fentanyl-induced cough (FIC) has a higher frequency in infants and children (6). Oshima and colleagues suggested that young age is one of the important contributing factors for the occurrence of FIC (7). Similarly, Yu et al. also observed a higher frequency of cough in infants and children induced by fentanyl in daily clinical practice (8). Limited studies have been accomplished to lower the rate of FIC in children $(9,10)$. It has been revealed that both mechanical and chemical-induced airway reflexes such as cough reflex, can be alleviated by intravenous lidocaine administration (11). Gecaj-Gashi et al. found that even a low dose of IV lidocaine can extensively subside fentanyl-induced cough among children (9). On the other hand, fentanyl was categorized as an antitussive drug with many advantages as mentioned earlier (1-3) and some research has been performed to evaluate effectiveness priming dose of fentanyl in preventing FIC in adult patients, with good results $(12,13)$. Since results of studies to suppression of FIC with lidocaine in children are very limited (9) and to date no research has been performed to evaluate effectiveness priming dose of fentanyl in preventing FIC in a pediatric population, we designed this study to compare the effectiveness of the pretreatment low dose of intravenous fentanyl with intravenous lidocaine on prevention of FIC in pediatric patients.

\section{Material and Methods}

\subsection{Trial design and participants}

This randomized clinical trial study was conducted between February and August 2017. This clinical trial study was conducted in an Iranian governmental educational, pediatric hospital (Motahari Hospital). This hospital is the referral center in Urmia, Iran. We selected the sample of study of all patients who had been referred to the hospital for herniorrhaphy under general anesthesia. Oral midazolam $(0.3 \mathrm{mg} / \mathrm{kg})$ was administered to all of the patients 20 minutes before separation from their parents. After arrival to the operating room, standard monitoring including electrocardiography, noninvasive blood pressure cuff, and pulse oximetry for vital sign recording; and intravenous line were established, then patients received atropine $(0.02 \mathrm{mg} / \mathrm{kg})$.

\subsection{Selection Criteria}

The inclusion criteria were: The Patients who were comparable with American Society of Anesthesiologis ts physical status (ASA) I or II (http:// www.asahg.org/clinical.physicalstatus.htm) aged 2-10 years, who were candidates for elective herniorrhaphy under general anesthesia. The exclusion criteria were: body weight exceeding $20 \%$ of the ideal body weight, emergency herniorrhaphy, a history of bronchial asthma, respiratory tract infection in recent 4 weeks, malformation of the tongue and oropharynx, and any medical history of allergy to local anesthetics. Figure 1 shows the CONSORT 2010 Flow Diagram of the study.

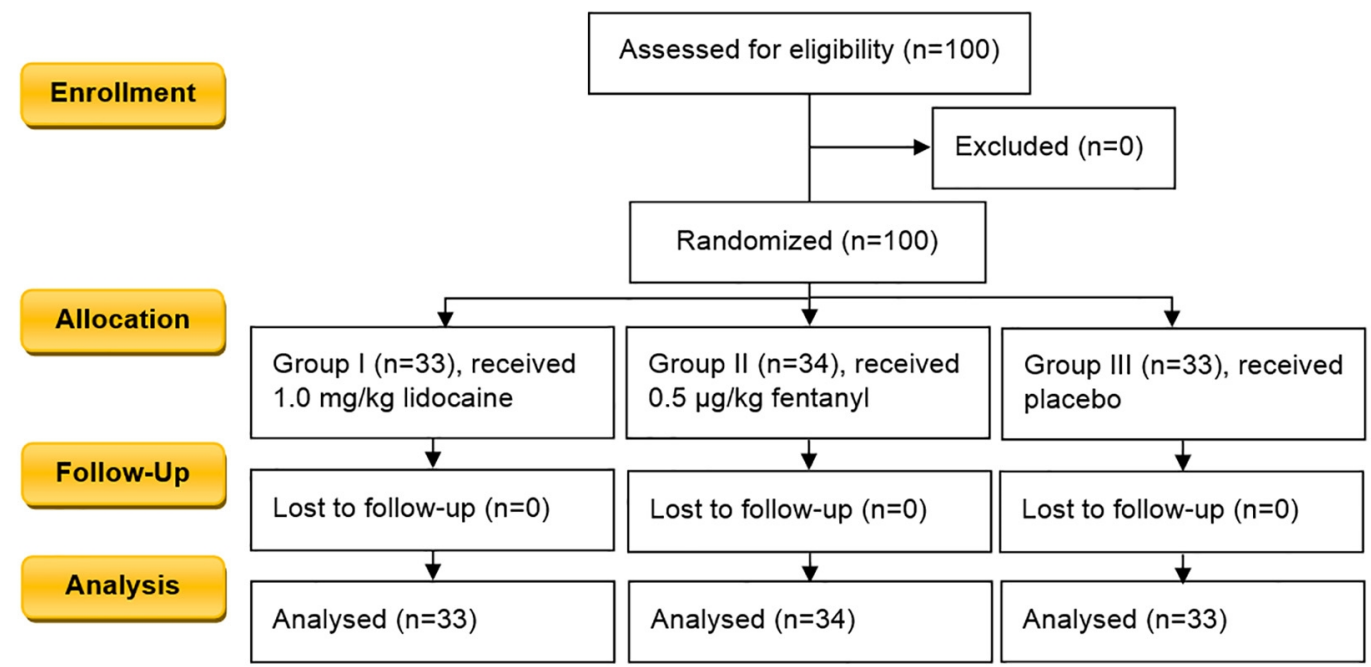

Figure 1. CONSORT 2010 Flow Diagram of the study 


\subsection{Intervention}

The interventions in this study were defined as intravenous $1.0 \mathrm{mg} / \mathrm{kg}$ lidocaine (Lidocaine was produced by Aburaihan Pharmaceutical Co. Tehran-Iran) or $0.5 \mu \mathrm{g} / \mathrm{kg}$ fentanyl (Fentanyl was a product of Darou Pakhsh Pharmaceutical Mfg. Co. Tehran-Iran) which was administered just one minute prior to the IV administration of 2 $\mu \mathrm{g} / \mathrm{kg}$ fentanyl to induce general anesthesia. The control group, who received Normal Saline, were compared with two invention arms to determine the study outcomes. A trained nurse who was blinded to patients' allocation prepared the syringes containing lidocaine, fentanyl, and normal saline just before induction of general anesthesia.

\subsection{Outcomes}

The primary outcome was defined as the cough incidence in each group. The time of onset and severity of cough were secondary outcomes in this study. After fentanyl injection, the time of onset and severity of cough were observed for two minutes and recorded by an anesthesiologist resident who was blinded to the study groups which had been given to the patients. The severity of cough was graded into three categories based on previous studies (9, 10,12 ) from the number of induced coughs (mild, 1-2; moderate, $3-4$; and severe, $\geq 5$ ). Assisted mask ventilation with oxygen was applied in cases which they had $\mathrm{SpO}_{2}$ less than 95\%, apnea, and/or muscle rigidity after fentanyl administration (these instances were also recorded). Apnea was defined as a pause in breathing that lasts more than 15 seconds. A muscle tone that imposed difficult or impossible ventilation was considered as muscle rigidity. Finally, anesthesia was induced with propofol $2 \mu \mathrm{g} / \mathrm{kg}$ and atracurium $0.5 \mathrm{mg} / \mathrm{kg}$ and maintained with isoflurane 1.3 $\%$ and a mixture of oxygen and nitrous oxide ( $50 \%$ for each).

\subsection{Sample size}

The sample size of the study was calculated based on the previous paper) 10) demonstrating 34\% of FIC incidence and assuming that the odds of developing cough in intervention arm relative to control group are $5 \%$. We needed to study 28 case patients and 28 control patients to be able to reject the null hypothesis that this odds ratio equals 1 with probability (power) 0.8 . The sample size was increased to 33 patients per group considering the sample attrition for any reason.

\subsection{Randomization and blinding}

One hundred patients were recruited as eligible population and assigned to one of three arms by using computer generated numbers. A concealed envelope was used to assign participants for each arm. A trained nurse was responsible for randomization. Group I received $1.0 \mathrm{mg} / \mathrm{kg}$ lidocaine (Group I n=33), Group II received $0.5 \mu \mathrm{g} / \mathrm{kg}$ fentanyl (Group II $n=34$ ) and, Group III received placebo [equal volume of $0.9 \%$ saline] (Group III $n=33$ ), one minute before the IV administration of $2 \mu \mathrm{g} / \mathrm{kg}$ fentanyl during induction of general anesthesia.

\subsection{Statistical methods}

Descriptive statistics were reported as mean (standard deviation) or median (interquartile range, IQR) for continuous variables and as frequency (percentage) for categorical variables. For comparisons of patients in intervention arms vs those in control group, chi-square tests were used to compare categorical variables. One way ANOVA and Kruskal-Wallis test were used to compare continuous variables, as appropriate. Multivariable logistic regression models were fit to explore the association between each intervention and control group with the presence of cough. The model was then adjusted for demographic characteristics (age, sex, weight) as potential confounder variables. Next, we adjusted for other covariates (So2, systolic blood pressure, heart rate). STATA software version 13 was used for analysis. Statistical significance was defined using a 2 -sided p-value $<0.05$ for all analyses.

\subsection{Research ethics}

The project was reviewed and approved by Urmia University of Medical Sciences Institutional Board. Medical ethics research committee of Urmia Medical Sciences University also approved the design of study (Ref. no.: IR.UMSU.REC.1394.386). This study was restarted in the Iranian Registry Clinical Trial (irct.ir) with IRCT number 2016112027677N5. The aim of the study and possible harm were explained to each participants' parents. Parents signed the consent form to confirm their awareness of all procedures.

\section{Results}

One hundred patients participated in this study. There was no statistically significant difference in patients' characteristics across three groups (Table 1). Comparing the mean of blood pressure (BP), heart rate (HR) and saturated pressure of oxygen $\left(\mathrm{SpO}_{2}\right)$ before and after drug injection, showed no statistical differences. The placebo group was more likely to have cough (54.5\%). In Group II, 32.4\% (11patients) had cough, whereas, in Group I, 
$21.2 \%$ ( 7 patients) had cough. There was a significant difference in the occurrence of cough across three groups $(\mathrm{p}=$ 0.02). The results of the study also showed a significant difference in the incidence of cough between the first and the third groups $(p=0.005)$ and between the second and the third groups $(p=0.045)$ as seen in Table 2 . No statistically significant differences have been detected between group one and two $(\mathrm{p}=0.07)$. The severity of cough was significantly higher in Group III compared to Group I and Group II ( $50 \%$ vs. $14.3 \%, 27.3 \%$ respectively, $\mathrm{p} \leqslant 0.016)$. As shown in Table 2, there was no significant difference between Group I and Group II in this regard ( $>0.05$ ). Furthermore, the time of onset of cough was similar across all groups (Table 2). None of the patients in the three groups suffered from hypoxemia, desaturation, apnea, truncal rigidity or other adverse effects. We examined the association of each intervention and presenting cough by using logistic regression analysis. As shown in Table 2, the first unadjusted model showed a lower odds of cough incidence associated with the intervention group (Group I OR: 0.78, 95\% CI: 0.39-0.91; and Group II OR: 0.83, 95\% CI: 0.41-0.85; Table 3). A similar result was found after adjusting for demographic variables (age, sex, weight,). Further adjustment for clinical characteristics $\left(\mathrm{SpO}_{2}\right.$, blood pressure, and heart rate) did not meaningfully change the association (Table 2).

Table 1. Baseline demographic and clinical characteristics among patients

\begin{tabular}{|l|l|l|l|l|}
\hline Characteristics & Group I $(\mathrm{n}=33)$ & Group II $(\mathrm{n}=34)$ & Group III $(\mathrm{n}=33)$ & p-value \\
\hline Age (year); Mean $\pm \mathrm{SD}$ & $4.39 \pm 2.99$ & $4.38 \pm 2.67$ & $5.00 \pm 3.41$ & 0.63 \\
\hline Weight (kg); Mean \pm SD & $18.84 \pm 7.96$ & $20.53 \pm 1.27$ & $18.35 \pm 7.11$ & 0.47 \\
\hline Heart rate (beat $/ \mathrm{min}) ;$ Mean \pm SD & $123.78 \pm 20.27$ & $121.79 \pm 9.15$ & $124.24 \pm 16.93$ & 0.803 \\
\hline $\mathrm{SpO}_{2}(\%) ;$ Mean $\pm \mathrm{SD}$ & $97.27 \pm 1.52$ & $124.32 \pm 5.2$ & $97.60 \pm 1.72$ & 0.07 \\
\hline Systolic blood pressure $(\mathrm{mmHg}) ;$ Mean $\pm \mathrm{SD}$ & $123.03 \pm 14.37$ & $122.35 \pm 14.32$ & $123.17 \pm 13.36$ & 0.96 \\
\hline \% Male (95\% CI) & $75(45-89)$ & $73(41-87)$ & $78(53-95)$ & 0.88 \\
\hline
\end{tabular}

$\mathrm{SPO}_{2}$ : Saturated $\mathrm{o}_{2}$ pressure

Table 2. Comparing the frequency of cough, cough severity, and time of cough onset after fentanyl

\begin{tabular}{|l|l|l|l|l|l|}
\hline Study Groups & Group I (n=33) & Group II (n=34) & Group III (n=33) & p-value \\
\hline \multicolumn{2}{|l|}{ Incidence of cough (\%) } & $21.2(17.3-4.8)$ & $32.4(21.3-41.6)$ & $54.5(47.3-60.0)$ & 0.02 \\
\hline Onset of cough (sec) & $4.57 \pm 2.87$ & $5.9 \pm 2.07$ & $5.94 \pm 2.95$ & 0.4 \\
\hline \multirow{2}{*}{ Severity of cough (\%) } & Mild & $71.4(60.4-80.5)$ & $45.5(37.4-59.9)$ & $22.2(17.6-30.2)$ & 0.01 \\
\cline { 2 - 5 } & Moderate & $14.3(11.0-18.3)$ & $27.3(21.2-33.8)$ & $27.8(22.3-36.4)$ & \\
\cline { 2 - 4 } & Sever & $14.3(11.0-18)$ & $27.3(21.2-33.8)$ & $50(43.7-55.6)$ & \\
\hline
\end{tabular}

Data are presented as Mean \pm SD or $95 \%$ CI

Table 3. Results of multivariable adjusted logistic regression examining the incidence of cough among study groups

\begin{tabular}{|c|c|c|c|c|c|c|}
\hline Study group & Unadjusted & & socio-demographi & adjusted & $\begin{array}{l}\text { clinical covariate } \\
\text { adjusted }\end{array}$ & \\
\hline Placebo & OR $(95 \% \mathrm{CI})$ & $\mathrm{p}$-value & OR $(95 \% \mathrm{CI})$ & p-value & OR $(95 \% \mathrm{CI})$ & p-value \\
\hline Group I & $0.78(0.39-0.91)$ & 0.01 & $0.77(0.37-0.90)$ & 0.01 & $0.78(0.39-0.90)$ & 0.001 \\
\hline Group II & $0.83(0.41-0.85)$ & 0.02 & $0.80(90.45-0.87)$ & 0.02 & $0.81(0.40-0.83)$ & 0.02 \\
\hline Male Gender & & & $1.65(0.84-3.12)$ & 0.22 & $1.10(0.44-2.72)$ & 0.18 \\
\hline Age (year) & & & $1.2(0.88-7.1)$ & 0.21 & $1.22(0.56-2.62)$ & 0.60 \\
\hline Weight $(\mathrm{Kg})$ & & & $1.46(0.68-3.2)$ & 0.32 & $2.05(0.89-4.72)$ & 0.08 \\
\hline Saturated $\mathrm{O}_{2}(\%)$ & & & & & $1.65(0.84-3.12)$ & 0.22 \\
\hline Heart rate (beat/min) & & & & & $1.64(0.75-3.44)$ & 0.24 \\
\hline $\begin{array}{l}\text { Systolic blood pressure } \\
(\mathrm{mmHg})\end{array}$ & & & & & $2.1(0.89-4.78)$ & 0.18 \\
\hline
\end{tabular}

\section{Discussion}

OR: Odds Ratio

Induction of general anesthesia with fentanyl usually causes fentanyl-induced cough (FIC), especially in children (1, 6). In this study we assessed both lidocaine and fentanyl in suppression of FIC in children and compared these two drugs with each other which, before this time, had not been done. We demonstrated that pre-treatment with $1 \mathrm{mg} / \mathrm{kg}$ of lidocaine, or $0.5 \mathrm{mg} / \mathrm{kg}$ of fentanyl one minute prior to fentanyl administration is an efficient approach to suppress fentanyl-induced cough compared to placebo. At first our study showed that administration of $2 \mu \mathrm{g} / \mathrm{kg}$ fentanyl induced cough reflex in $54.5 \%$ of patients in the placebo group that was higher than a previous report (43.4\%) by Gecaj-Gashi et al. (9). This discrepancy may be due to the different speeds of fentanyl injection or the 
injected dose of fentanyl in two studies $(3,14)$. But incidence of FIC in lidocaine group between our study and similar study was almost equal $(22.6 \%$ versus $21.2 \%)$. It is still not clear how lidocaine suppresses cough after injection of fentanyl, but it has been proposed that cough suppression can be induced by depression of brain stem functions. An alternate mechanism is that lidocaine may deactivate peripheral cough receptors in the trachea and hypopharynx (15). We found that IV lidocaine with a dose of $1 \mathrm{mg} / \mathrm{kg}$ can markedly (78.8\%) prevent fentanylinduced cough in pediatric patients during induction of general anesthesia.

As already mentioned, the interventions regarding effects of priming the dose of fentanyl on FIC have been performed only between adult patients, for this reason we studied the effect of priming low dose fentanyl on incidence of FIC in children. Therefore, based on previous published results by $\mathrm{Gu}$ et al. (12), we have accomplished a similar study on a child population and found that administration of low dose fentanyl $(0.5 \mu \mathrm{g} / \mathrm{kg})$ as pretreatment dose, can be effective in suppression of FIC in pediatric patients (32.4\%), as well as adults (12). Fentanyl was categorized as an antitussive drug due to its ability to inhibit the mu receptor in the lung (peripherally action), and suppress the cough center in the medulla oblongata (centrally action) $(16,17)$, but this drug frequently elicits cough within a few seconds after drug injection. Precise mechanisms of FIC have not been clearly defined. Some suggestions include: 1) A pulmonary chemoreflex, mediated by either irritant-receptors [rapidly adapting receptors] or by vagal C-fiber receptors that are in proximity to pulmonary vessels (juxta-capillary receptors) (3); 2) Irritant receptors stimulation in the upper pulmonary mucosa secondary to fentanyl induced tracheal smooth muscle constriction (18); 3) Histamine release from lung mast cells (19); 4) Sudden adduction of the vocal cords or supraglottic obstruction by soft tissue induced by opioid causing muscle rigidity (20). Based on some opinions, FIC in children could be related to the intensive action of the irritant receptor (rapidly adapting receptors), which interpose the pulmonary chemoreflex in the tracheal smooth muscle. Also, the decreasing number of rapidly adapting receptors with age in an animal study was demonstrated $(21,22)$. This action has probably been accomplished by the releasing of neurotransmitters that do not reach the threshold to induce cough. However, based on some studies, administrating the higher dose of fentanyl may cause an exhaustion of these neurotransmitters which lead to reduction of cough frequency $(12,23)$. With this research, we found that injection of $0.5 \mu \mathrm{g} / \mathrm{kg}$ fentanyl as a priming dose can diminish the rate of FIC by $70 \%$ in children. $(12,13)$. In our study, frequency of FIC in the fentanyl group was a little more than in the lidocaine group (32.4\% versus $22.6 \%)$ but this difference was not significant and even severity of cough between two groups was similar. Thus, this indicates that both fentanyl and lidocaine can supress FIC in children, with high efficacy. Most of the trials have reported smooth and benign cough, which is consistent with our patients' outcomes $(6,9,19,24)$, but Tweed and Dakin (4) reported a manifestation of an explosive cough in a 7-yr-old boy with Down syndrome due to injection of IV fentanyl $(2 \mu \mathrm{g} / \mathrm{kg})$ that led to periorbital petechial and it subsided only after induction of general anesthesia. Also, Ambesh et al. (5) described a 12-year-old patient (case of arteriovenous malformation of tongue and oropharynx) with an intensive cough after prescribing $50 \mu \mathrm{g}$ of IV fentanyl that caused acute airway obstruction and severe hypoxia because of massive swelling of the tongue and hypopharynx. Thus with this research, we came to the conclusion that use of fentanyl or lidocaine for prevention of FIC in high risk pediatric patients could be very useful. This study had some limitations which affect the interpretation of these data. First, there are only three groups in our study and we could not determine the effect of different dosages of lidocaine or fentanyl on FIC. Second, there have been few studies concerning the prevention of FIC in children. Thus, additional RCTs are needed.

\section{Conclusions}

Based on this study, we conclude that both pretreatment doses of fentanyl and lidocaine can equally supress fentanyl induced cough in children. We suggest additional study for the assessment of different priming doses of fentanyl or lidocaine for prevention of FIC during induction of general anesthesia in pediatric settings.

\section{Acknowledgments:}

We are grateful to our colleagues for their cooperation and interest during the study period, in the Motahari Hospital Medical Center, affiliated to the Urmia University of Medical Sciences, in Urmia, Iran.

\section{Trial registration:}

The Trial was registered at the Iranian Registry of Clinical Trials (http://WWW.irct.ir) with IRCT number: IRCT2016112027677N5.

\section{Funding:}

We confirm that this study was not granted or funded by any institution. 


\section{Conflict of Interest:}

There is no conflict of interest to be declared.

\section{Authors' contributions:}

All authors contributed to this project and article equally. All authors read and approved the final manuscript.

\section{References:}

1) Miller DR, Cohen NH, Erikson LI, Fleisher LA, Wiener-Kronish JP, Young WL. Miller's Anesthesia. $2015 ; 31,94: 877-8,2769$.

2) Adachi YU, Satomoto M, Higuchi H, Watanabe K. Fentanyl attenuates the hemodynamic response to endotracheal intubation more than the response to laryngoscopy. Anesth Analg. 2002; 95: 233-7. doi: 10.1097/00000539-200207000-00043. PMID: 12088976.

3) Bohrer H, Fleischer F, Werning P. Tussive effect of a fentanyl bolus administered through a central venous catheter. Anaesthesia. 1990; 45: 18-21. doi: 10.1111/j.1365-2044.1990.tb14496.x. PMID: 2316832.

4) Tweed WA, Dakin D. Explosive coughing after fentanyl injection. Anesth Analg. 2001; 92: 1442-5. doi: 10.1097/00000539-200106000-00018. PMID: 11375822.

5) Ambesh SP, Singh N, Srivastava K. Fentanyl induced coughing caused life threatening airway obstruction in a patient with arteriovenous malformation of tongue and hypopharynx. Internet J Anesthesiol. 2009; 20: 1.

6) Han JI, Lee H, Kim CH, Lee GY. The frequency of fentanyl-induced cough in children and its effects on tracheal intubation. J Clin Anesth. 2010; 22: 3-6. PMID: 20206844. doi: 10.1016/j.jclinane.2009.01.019.

7) Oshima $T$, Kasuya $Y$, Okumura $Y$, Murakami $T$, Dohi S. Identification of independent risk factors for fentanyl-induced cough. Can J Anaesth. 2006; 53: 753-8. doi: 10.1007/BF03022790. PMID: 16873340.

8) Yu H, Yang XY, Zhang X, Li Q, Zhu T, Wang Y, et al. The effect of dilution and prolonged injection time on fentanyl-induced coughing. Anaesthesia. 2007; 62: 919-22. doi: 10.1111/j.1365-2044.2007.05147.x. PMID: 17697219.

9) Gecaj-Gashi A, Nikolova-Todorova Z, Ismaili-Jaha V, Gashi M. Intravenous lidocaine suppresses fentanylinduced cough in Children. Cough. 2013; 9: 20. doi: 10.1186/1745-9974-9-20. PMID: 23947795, PMCID: PMC3751768.

10) Kim DH, Yoo JY, Moon BK, Yoon BH, Kim JY. The effect of injection speed on remifentanil-induced cough in children. Korean J Anesthesiol. 2014; 67(3): 171-4. doi: 10.4097/kjae.2014.67.3.171. PMID: 25301090, PMCID: PMC4188761.

11) Baraka A. IV lidocaine controls extubation laryngospasm in children. Anesth Analg. 1978; 57: 506-7. doi: 10.1213/00000539-197807000-00028. PMID: 360878.

12) Gu C, Zhou M, Wu H, Li E, Tang C. Effects of different priming doses of fentanyl on fentanyl-induced cough: A double-blind randomized controlled study. Pharmacol Rep. 2012; 64(2): 321-5. PMID: 22661182.

13) Du BX, Cao L, Zhao WL, Xu ZH, Song J, Shi XY. Pre-emptive small dose of fentanyl suppresses fentanylinduced cough: a meta-analysis of randomized controlled trials. Int J Clin Exp Med. 2014; 7(4): 826-36. PMID: 24955151, PMCID: PMC4057830.

14) Lui PW, Hsing $\mathrm{CH}$, Chu YC. Terbutaline inhalation suppresses fentanyl induced coughing. Can J Anaesth 1996; 43: 1216-9. doi: 10.1007/BF03013427. PMID: 8955969.

15) Poulton TJ, James FR. Cough suppression by lidocaine. Anes- thesiology. 1979; 50: 470-2. PMID: 453567.

16) Fuller Rv, Jackson DM. Physiology and treatment of cough. Thorax. 1990; 45: 425-30. PMID: 2203180, PMCID: PMC462522.

17) Young EC, Smith JA. Pharmacologic therapy for cough. Curr Opin Pharmacol. 2011; 11(3): 224-30. PMID: 21724464. doi: 10.1016/j.coph.2011.06.003.

18) Yasuda I, Hirano $T$, Yusa $T$, Satoh $M$. Tracheal constriction by morphine and by fentanyl in man. Anesthesiology. 1978; 49: 117-9. PMID: 686415.

19) Agarwal A, Azim A, Ambesh S, Bose N, Dhiraj S, Sahu D, et al. Salbutamol, beclomethasone or so- dium chromoglycate suppress coughing induced by iv fentanyl. Can J Anaesth. 2003; 50: 297-300. PMID: 12620955. doi: 10.1007/BF03017801.

20) Lin CS, Sun WZ, Chan WH, Lin CJ, Yeh HM, Mok MS. Intravenous lidocaine and ephedrine, but not propofol, suppress fentanyl- induced cough. Can J Anaesth. 2004; 51: 654-9. doi: 10.1007/BF03018421. PMID: 15310631. 
21) Benthuysen JL, Smith NT, Sanford TJ, Head N, Dec-Silver H. Physiology of alfentanil-induced rigidity. Anesthesiology.1986; 64: 440-6. PMID: 3008595.

22) Pontoppidan H, Beecher HK. Progressive loss of protective reflexes in the airway with the advance of age. JAMA. 1960; 174: 2209-13. doi: 10.1001/jama.1960.03030180029007. PMID: 13737040.

23) Jung HJ, Kim JB, Im KS, Cho HJ, Kim JW, Lee JM. Effects of a priming dose of fentanyl during anaesthesia on the incidence and severity of fentanyl-induced cough in current, former and non-smokers. Int Med Res. 2011; 39(6): 2379-84. doi: 10.1177/147323001103900638. PMID: 22289557.

24) Honarmand A, Safavi M, Khalighinejad F. A comparison of the effect of pretreatment with intravenous dexamethasone, intravenous ketamine, and their combination, for suppression of remifentanil-induced cough: A randomized, double-blind, placebo-controlled clinical trial. Adv Biomed Res. 2013; 2: 60. doi: 10.4103/2277-9175.115808. PMID: 24223375, PMCID: PMC3814903. 